\title{
BMJ Open Natalizumab versus fingolimod for patients with active relapsing-remitting multiple sclerosis: results from REVEAL, a prospective, randomised head-to-head study
}

Helmut Butzkueven, ${ }^{1,2}$ Stephanie Licata (D) , ${ }^{3}$ Douglas Jeffery, ${ }^{4}$ Douglas L Arnold, ${ }^{5,6}$ Massimo Filippi, ${ }^{7}$ Jeroen JG Geurts, ${ }^{8}$ Sourav Santra, ${ }^{9}$ Nolan Campbell, ${ }^{3}$ Pei-Ran $\mathrm{Ho},{ }^{9}$ on behalf of the REVEAL Investigators

To cite: Butzkueven $\mathrm{H}$, Licata S, Jeffery $\mathrm{D}$, et al. Natalizumab versus fingolimod for patients with active relapsing-remitting multiple sclerosis: results from REVEAL, a prospective, randomised head-to-head study. BMJ Open 2020;10:e038861. doi:10.1136/ bmjopen-2020-038861

- Prepublication history and additional material for this paper are available online. To view these files, please visit the journal online (http://dx.doi. org/10.1136/bmjopen-2020038861).

Received 26 March 2020 Revised 02 September 2020 Accepted 03 September 2020

Check for updates

(c) Author(s) (or their employer(s)) 2020. Re-use permitted under CC BY-NC. No commercial re-use. See rights and permissions. Published by BMJ.

For numbered affiliations see end of article.

Correspondence to

Dr Stephanie Licata;

stephanie.licata@biogen.com

\section{ABSTRACT}

Objective To directly compare the efficacy of natalizumab and fingolimod in patients with active relapsing-remitting multiple sclerosis.

Methods This phase 4, randomised, rater- and sponsorblinded, prospective, parallel-group, clinic-based head-tohead study was conducted at 43 sites in nine countries. Patients were randomised (1:1) to intravenous natalizumab $300 \mathrm{mg}$ every 4 weeks or oral fingolimod $0.5 \mathrm{mg}$ once daily for $\leq 52$ weeks. Enrolment-related early study termination precluded assessment of the primary endpoint (evolution of new on-treatment gadolinium-enhancing $(\mathrm{Gd}+)$ lesions to persistent black holes). Unplanned exploratory analyses of secondary endpoints evaluated the effects of treatment on the development of new T1 Gd+ lesions and new/ newly enlarging T2 lesions, lesion volumes and relapse outcomes.

Results The intent-to-treat population comprised 108 patients (natalizumab, $n=54$; fingolimod, $n=54$ ); 63 completed $\geq 24$ weeks of treatment. Due to the limited numbers of events and patients at risk, MRI and relapse outcomes were reported over up to 24 and 36 weeks, respectively. The mean number of new $\mathrm{T} 1 \mathrm{Gd}+$ lesions was numerically lower with natalizumab than with fingolimod by 4 weeks; accumulation rates were 0.02 and 0.09 per week, respectively, over 24 weeks $(p=0.004)$. The cumulative probability of developing $\geq 1$ lesion at 24 weeks was $40.7 \%$ with natalizumab versus $58.0 \%$ with fingolimod $(\mathrm{HR}=0.60 ; 95 \% \mathrm{Cl} 0.31-1.16 ; \mathrm{p}=0.126)$; the corresponding probabilities for $\geq 2$ lesions were $11.5 \%$ vs $48.5 \%$ ( $H R=0.25$; $95 \% \mathrm{Cl} 0.09-0.68 ; p=0.007)$. No significant between-group differences were observed for the other MRI outcomes at 24 weeks. The cumulative probability of relapse over follow-up was $1.9 \%$ with natalizumab versus $22.3 \%$ with fingolimod ( $\mathrm{HR}=0.08 ; 95 \% \mathrm{Cl} 0.01-0.64 ; \mathrm{p}=0.017$ ). Adverse events were consistent with known safety profiles.

Conclusions These results suggest that natalizumab is more efficacious than fingolimod in reducing multiple sclerosis relapses and $\mathrm{T} 1 \mathrm{Gd}+$ lesion accumulation in patients with active disease.

Trial registration numbers NCT02342704; EUCTR2013004622-29-IT; Post-results.

\section{Strengths and limitations of this study}

- This study is the first randomised controlled trial to compare the efficacy of natalizumab and fingolimod in patients with relapsing-remitting multiple sclerosis.

- The primary endpoint, evolution of new on-treatment gadolinium-enhancing lesions to persistent black holes, could not be assessed due to early study termination.

- Secondary endpoints, including the effects of treatment on the development of new T1 gadoliniumenhancing lesions and new/newly enlarging T2 lesions, lesion volumes and relapse outcomes, were assessed over a relatively short treatment period of 24-36 weeks.

\section{INTRODUCTION}

Natalizumab and fingolimod are wellestablished, efficacious disease-modifying therapies for relapsing-remitting multiple sclerosis (RRMS), demonstrating reductions in clinical and radiological measures of disease activity in pivotal placebo-controlled trials. ${ }^{1-5}$ Previous analyses have indicated that both natalizumab and fingolimod exhibit beneficial effects quickly (within 2 months) after treatment initiation, ${ }^{6-9}$ which may be an important consideration in treatment selection, especially in patients with active disease. However, evidence regarding the relative efficacy of natalizumab and fingolimod has, to date, been limited to retrospective analyses of registry datasets. ${ }^{10-22}$ While the majority of these studies reported improved outcomes with natalizumab compared with fingolimod, ${ }^{10}{ }^{12-15}{ }^{18-21}$ several found no difference in clinical outcomes between the two therapies. ${ }^{16}$ However, one study found that the 
reduction in annualised relapse rate (ARR) after 1 year of treatment was significantly greater with natalizumab than with fingolimod, whereas treatment persistence was significantly higher in patients treated with fingolimod. ${ }^{22}$

This study reports results from REVEAL, a 1-year, randomised, rater-blinded and sponsor-blinded, prospective head-to-head study comparing natalizumab and fingolimod in patients with active RRMS. Although early study closure precluded analysis of the primary efficacy endpoint, available MRI data were used in unplanned exploratory analyses of secondary endpoints to directly compare natalizumab versus fingolimod efficacy within 4 weeks of therapy initiation. In addition, relapse data were analysed to assess ARRs and the cumulative probability of relapse over the duration of the study.

\section{METHODS}

REVEAL was a phase 4, randomised, rater- and sponsorblinded, prospective, parallel-group, clinic-based headto-head study conducted at 43 sites in nine countries between October 2014 and May 2016 (planned overall duration, 68 weeks) in accordance with the Declaration of Helsinki and Good Clinical Practice Guidelines (clinicaltrials.gov identifier NCT02342704; EudraCT identifier EUCTR2013-004622-29-IT). ${ }^{23}$ The REVEAL investigators are listed in online supplemental table 1 . All sites received institutional review board approval (see online supplemental table 2), and all participants provided written informed consent. REVEAL was designed to include approximately 540 patients. However, after 1 year of enrolling patients, only 111 patients had been enrolled. The decision to terminate the study due to slow enrolment was made by the sponsor (Biogen) in November 2015. Outcome data were not made available until May 2016, and all scheduled MRI scans were evaluated in a blinded manner. Thus, the study termination decision was made without knowledge of the results.

Patients were aged 18-60 years and had active RRMS not previously treated with natalizumab, fingolimod or immunosuppressants, with $\geq 1$ new $\mathrm{T} 1$ gadoliniumenhancing $(\mathrm{Gd}+)$ lesion within the 6 months prior to screening or $\geq 2$ new T2 lesions on brain MRI within the 6 months prior to screening (compared with a T2-weighted scan 18 months before screening) as well as an Expanded Disability Status Scale (EDSS) score $\leq 5.5$. Included patients could have previously been treated for $\geq 6$ months with glatiramer acetate or an interferon beta formulation if they had $\geq 9$ T2-hyperintense lesions on brain MRI and experienced $\geq 1$ relapse while on therapy within the 6 months prior to screening. Multiple sclerosis (MS) treatment-naïve patients and patients who had previously been treated for $<6$ months with glatiramer acetate or an interferon beta formulation were included only if they had $\geq 2$ disabling relapses within the 12 months prior to screening. Patients with progressive MS were excluded.

Following a 4-week screening period, patients were randomly assigned (1:1) to open-label intravenous natalizumab $300 \mathrm{mg}$ every 4 weeks or oral fingolimod $0.5 \mathrm{mg}$ once daily for up to 52 weeks, then followed for up to 64 weeks. MRI scans were scheduled every 4 weeks for the first 24 weeks and then at 36 and 52 weeks. A follow-up visit approximately 12 weeks after the last dose of study drug was planned.

Relapses and adverse events (AEs) were assessed at scheduled visits. A clinical relapse was defined as new or recurrent neurological symptoms, not associated with fever, lasting for at least 24 hours and followed by a period of 30 days of stability or improvement. New or recurrent neurological symptoms that occurred fewer than 30 days after the onset of a protocol-defined relapse were considered part of the same relapse. MS relapses were not considered AEs, and MS relapses resulting in hospitalisation did not need to be reported as serious AEs (SAEs). However, any MS relapse that was complicated by other SAEs was reported as an SAE.

The intent-to-treat (ITT) population for efficacy analysis comprised all randomised subjects given $\geq 1$ dose of study drug who provided any efficacy assessments. The primary endpoint (the evolution of new on-treatment T1-weighted Gd+ lesions to persistent black holes over 52 weeks) could not be assessed due to the lack of 52-week data. Secondary endpoints included the number of new T1 Gd+ lesions, the cumulative probability of developing new T1 Gd+ lesions, the number of new/newly enlarging T2 lesions, T1 and T2 lesion volumes and relapse outcomes. MRI and relapse outcomes were assessed over the study duration according to the protocol. However, due to the limited numbers of events and patients at risk, MRI outcomes were reported over up to 24 weeks, while relapse outcomes were reported over up to 36 weeks. Other secondary endpoints, including the time to complete recovery from the first relapse, proportion of patients with no evidence of disease activity and change from baseline in information processing speed as measured by the Symbol Digit Modalities Test, were not interpretable due to the early closure of the study. Safety was assessed based on AEs, laboratory measurements, vital signs and physical examinations.

Treatment groups were compared using negative binomial regression models, and Cox regression models were developed for probability analyses. P values for comparisons in new T2 lesions and lesion volume changes were determined using a Wilcoxon rank-sum test.

A diffusion tensor imaging substudy, which included healthy volunteers, was conducted to assess brain tissue damage and recovery in patients with active RRMS. Due to study termination, results were unevaluable.

\section{Patient involvement}

Patients were not involved in the design, conduct, reporting or dissemination of this research.

\section{RESULTS}

The ITT population (table 1) comprised 108 patients (see online supplemental figure 1); 63 patients $(58.3 \%$; 
Table 1 Baseline demographics and characteristics

\begin{tabular}{|c|c|c|}
\hline Characteristic & $\begin{array}{l}\text { Natalizumab } \\
(n=54)\end{array}$ & $\begin{array}{l}\text { Fingolimod } \\
(n=54)\end{array}$ \\
\hline \multicolumn{3}{|l|}{ Age, years } \\
\hline Mean (SD) & $38.2(8.8)$ & $34.9(8.7)$ \\
\hline Median (min, max) & $40(21,55)$ & $35(19,55)$ \\
\hline Sex, n (\%) female & $37(68.5)$ & $38(70.4)$ \\
\hline \multicolumn{3}{|l|}{ EDSS score } \\
\hline Mean (SD) & $2.5(1.3)$ & $2.6(1.3)$ \\
\hline Median (min, max) & $2.0(0.0,6.0)$ & $2.5(0.0,5.5)$ \\
\hline $\begin{array}{l}\text { Time since the first MS symptoms, mean } \\
\text { (SD), years }\end{array}$ & $8.1(7.7)$ & $6.8(7.0)$ \\
\hline $\begin{array}{l}\text { Time since MS diagnosis, mean (SD), } \\
\text { years }\end{array}$ & $5.0(5.8)$ & $4.5(5.8)$ \\
\hline Prior MS treatment, $n(\%)$ of patients ${ }^{\star}$ & $26(48.1)$ & $28(51.9)$ \\
\hline $\begin{array}{l}\text { Time since most recent relapse, mean } \\
\text { (SD), days }\end{array}$ & $86.8(58.8)$ & $91.2(91.4)$ \\
\hline $\begin{array}{l}\text { Number of relapses in the past year, } \\
\text { mean (SD) }\end{array}$ & $1.9(0.7)$ & $1.9(0.6)$ \\
\hline \multicolumn{3}{|l|}{ Number of Gd+ lesions } \\
\hline Mean (SD) & $2.4(3.7)$ & $2.5(4.9)$ \\
\hline Median (min, max) & $1(0,14)$ & $1(0,28)$ \\
\hline \multicolumn{3}{|l|}{ T2 lesion volume, $\mathrm{mL}$} \\
\hline Mean (SD) & $11.9(9.4)$ & $10.9(10.4)$ \\
\hline Median (min, max) & $8.5(0.7,40.1)$ & $7.7(0.1,43.2)$ \\
\hline \multicolumn{3}{|l|}{ T1-non-enhancing lesion volume, $\mathrm{mL}$} \\
\hline Mean (SD) & $2.3(2.4)$ & $2.4(3.4)$ \\
\hline Median (min, max) & $1.3(0,8.6)$ & $1.1(0,15.3)$ \\
\hline
\end{tabular}

*Most commonly glatiramer acetate (natalizumab, $n=7$; fingolimod, $n=9$ ) and interferon beta (subcutaneous (SC) interferon beta-1a: natalizumab, $n=10$; fingolimod, $n=6$; intramuscular interferon beta-1a: natalizumab, $n=4$; fingolimod, $n=10$; $S C$ interferon beta- $1 \mathrm{~b}$ : natalizumab, $n=1$, fingolimod, $n=5$; $S C$ interferon beta- $1 b$ : natalizumab, $n=1$, fingolimod, $n=2$ ).

EDSS, Expanded Disability Status Scale; Gd+, gadolinium enhanced; max, maximum; min, minimum; MS, multiple sclerosis.

natalizumab, $\mathrm{n}=32$; fingolimod, $\mathrm{n}=31$ ) received study treatment through 24 weeks, whereas only 3 (2.8\%; natalizumab, $\mathrm{n}=2$; fingolimod, $\mathrm{n}=1$ ) were treated through 52 weeks (table 2). Median (range) follow-up time was 40.1 (7.1-64.7) weeks for natalizumab and 36.7 (7.0-64.1) weeks for fingolimod.

The mean number of new T1 Gd+ lesions was $63 \%$ lower in the natalizumab group than the fingolimod group at 4 weeks $(p=0.353)$ and $\geq 70 \%$ lower at 12 weeks $(p=0.030$; figure 1), a difference that was maintained (with reduced patient numbers) through 24 weeks $(\mathrm{p}=0.008)$. Over 24 weeks, new T1 Gd+ lesion accumulation was lower among natalizumab-treated than fingolimod-treated patients (0.02 vs 0.09 new lesions per week; $p=0.004)$. Over the entire follow-up period, natalizumab-treated patients were significantly less likely than fingolimod-treated patients to develop $\geq 2$ or $\geq 3$ new T1 Gd+ lesions (table 3 ). No significant between-group differences were observed in other MRI outcomes at 24 weeks; however, all MRI results numerically favoured natalizumab (table 3 ).

During follow-up in this abbreviated study, natalizumabtreated patients were significantly less likely than fingolimod-treated patients to experience a relapse
Table 2 Treatment exposure and safety outcomes

\begin{tabular}{lll}
\hline Characteristic & $\begin{array}{l}\text { Natalizumab } \\
(\mathbf{n}=\mathbf{5 4})\end{array}$ & $\begin{array}{l}\text { Fingolimod } \\
(\mathbf{n}=54)\end{array}$ \\
\hline Study drug exposure, days & & \\
\hline Mean (SD) & $183.0(90.9)$ & $182.6(101.8)$ \\
\hline Median (range) & $197(1-364)$ & $172(1-362)$
\end{tabular}

Patients receiving treatment at each time point, $n(\%)$

\begin{tabular}{|c|c|c|}
\hline Baseline & $54(100)$ & $54(100)$ \\
\hline Week 4 & $52(96.3)$ & $50(92.6)$ \\
\hline Week 8 & $50(92.6)$ & $47(87.0)$ \\
\hline Week 12 & $45(83.3)$ & $45(83.3)$ \\
\hline Week 16 & $42(77.8)$ & $40(74.1)$ \\
\hline Week 20 & $36(66.7)$ & $35(64.8)$ \\
\hline Week 24 & $32(59.3)$ & $31(57.4)$ \\
\hline Week 32 & $25(46.3)$ & $23(42.6)$ \\
\hline Week 40 & $11(20.4)$ & $13(24.1)$ \\
\hline Week 52 & $2(3.7)$ & $1(1.9)$ \\
\hline Treatment-emergent AEs, $n(\%)$ of patients & $23(42.6)$ & $32(59.3)$ \\
\hline \multicolumn{3}{|c|}{ Most commonly reported events, $\mathrm{n}(\%)$ of patients ${ }^{\star}$} \\
\hline Headache & $6(11.1)$ & $4(7.4)$ \\
\hline MS relapse & $1(1.9)$ & $8(14.8)$ \\
\hline Hypoesthesia & 0 & $3(5.6)$ \\
\hline Migraine & 0 & $3(5.6)$ \\
\hline Upper respiratory tract infection & $1(1.9)$ & $5(9.3)$ \\
\hline Urinary tract infection & $2(3.7)$ & $3(5.6)$ \\
\hline Lymphocyte count decreased & 0 & $5(9.3)$ \\
\hline Alanine aminotransferase increased & 0 & $3(5.6)$ \\
\hline Anxiety & $1(1.9)$ & $3(5.6)$ \\
\hline Fatigue & $3(5.6)$ & 0 \\
\hline Oropharyngeal pain & $3(5.6)$ & $1(1.9)$ \\
\hline Serious AEs, $n(\%)$ of patients & 0 & $2(3.7)$ \\
\hline Second-degree atrioventricular block & 0 & $1(1.9)$ \\
\hline Migraine with aura & 0 & $1(1.9)$ \\
\hline $\begin{array}{l}\text { Events leading to study discontinuation, } n \\
(\%) \text { of patients } \dagger\end{array}$ & $1(1.9)$ & $3(5.6)$ \\
\hline Second-degree atrioventricular block & 0 & $1(1.9)$ \\
\hline Infusion site rash & $1(1.9)$ & 0 \\
\hline Alanine aminotransferase increased & 0 & $1(1.9)$ \\
\hline Aspartate aminotransferase increased & 0 & $1(1.9)$ \\
\hline Headache & 0 & $1(1.9)$ \\
\hline Patients who discontinued, $\mathrm{n}(\%)$ & $53(98.1) \ddagger$ & $51(94.4) \S$ \\
\hline
\end{tabular}

${ }^{*}$ Treatment-emergent AEs reported by $\geq 5 \%$ patients in either group, listed by MedDRA preferred term.

WWith the exception of atrioventricular block, AEs leading to study discontinuation were classified as non-serious events.

$\ddagger$ Forty-nine patients discontinued due to sponsor study termination, two were lost to follow-up, one discontinued due to an $\mathrm{AE}$ and one discontinued due to withdrawal of consent.

$\S$ Forty-three patients discontinued due to sponsor study termination, three discontinued due to AEs, three discontinued due to physician decision, one was lost to follow-up and one discontinued for another reason.

AE, adverse event; MedDRA, Medical Dictionary for Regulatory Activities; MS, multiple sclerosis.

(table 3). The cumulative probability of relapse over follow-up was $1.9 \%$ with natalizumab and $22.3 \%$ with fingolimod $\quad(\mathrm{HR}=0.08 ; \quad 95 \% \mathrm{CI} \quad 0.01-0.64 ; \quad \mathrm{p}=0.017$; figure 2A). Pre-treatment ARRs in the natalizumab and 


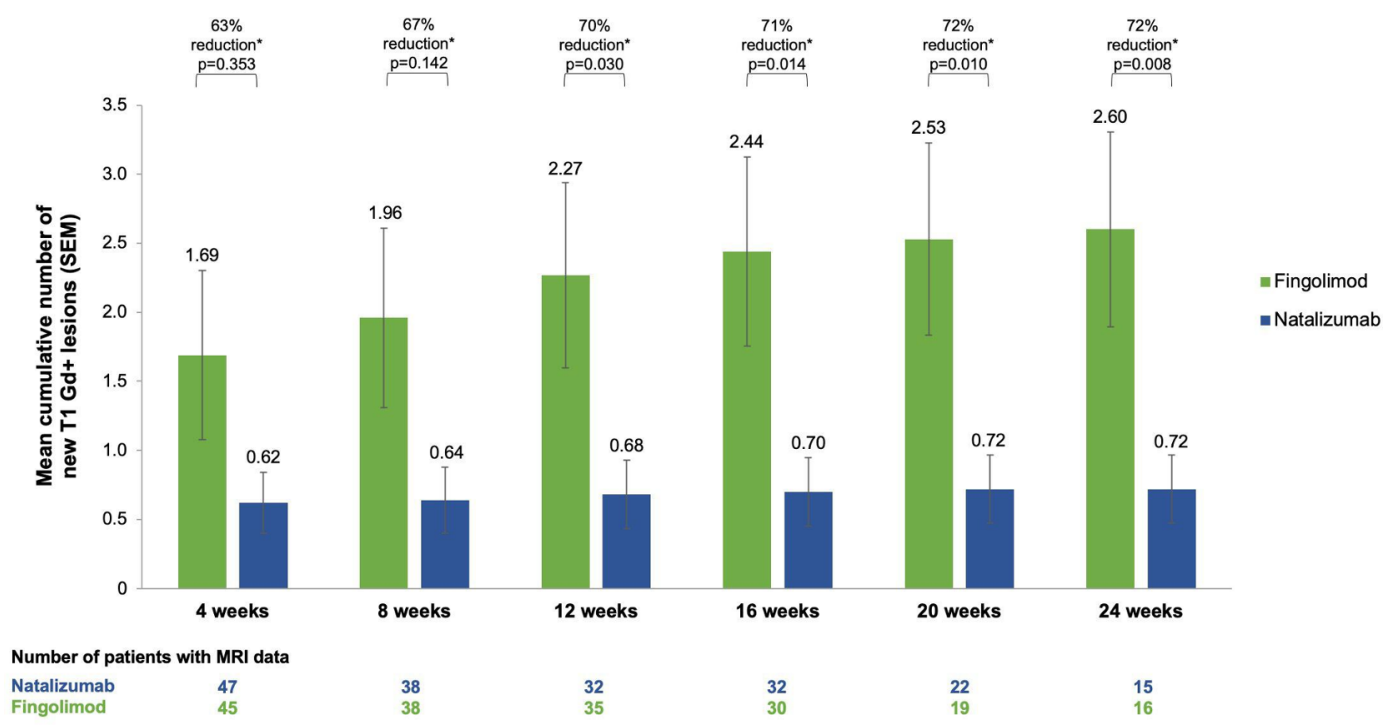

Figure 1 Mean cumulative number of new Gd+ lesions on T1-weighted MRI scans reported over 24 weeks. *Reduction is for natalizumab versus fingolimod. $\mathrm{P}$ value is based on a negative binomial regression model adjusted for baseline T1 Gd+ lesion count. Gd+, gadolinium enhancing; SEM, standard error of the mean.

\begin{tabular}{|c|c|c|c|c|}
\hline Outcomes & Natalizumab $(n=54)$ & Fingolimod $(n=54)$ & HR $(95 \% \mathrm{Cl})^{*}$ & $\mathbf{P}$ value \\
\hline \multicolumn{5}{|l|}{ MRI outcomes: T1 Gd+ lesions } \\
\hline$\geq 1$ & 40.68 & 57.99 & $0.60(0.31-1.16)$ & 0.126 \\
\hline$\geq 2$ & 11.54 & 48.48 & $0.25(0.09-0.68)$ & 0.007 \\
\hline $\begin{array}{l}\text { Number of patients with new T1 Gd+ lesions from } \\
\text { baseline to } 24 \text { weeks, n/N (\%) }\end{array}$ & 16/47 (34.0)† & $24 / 45(53.3) \ddagger$ & NA & 0.062 \\
\hline $\begin{array}{l}\text { Change from baseline in } \mathrm{T} 1 \mathrm{Gd}+\text { lesion vol to } 24 \\
\text { weeks, mean (SD) }\end{array}$ & $0.5(31.2) \S$ & $1.8(19.7) \S$ & NA & 0.532 \\
\hline \multicolumn{5}{|l|}{ MRI outcomes: T2 lesions } \\
\hline $\begin{array}{l}\text { Change from baseline in T2 lesion volume to } 24 \\
\text { weeks, mean (SD) }\end{array}$ & $0.1(4.4) \S$ & $3.3(5.0) \S$ & NA & 0.053 \\
\hline \multicolumn{5}{|l|}{ Relapse outcomes } \\
\hline Cumulative probability of relapse over study, \% & 1.9 & 22.3 & $0.08(0.01-0.64)^{\star *}$ & 0.017 \\
\hline ARR on study $(95 \% \mathrm{Cl})$ & $0.02(0.00-0.13)$ & $0.20(0.11-0.37)$ & $0.09(0.01-0.72) \dagger \dagger$ & $0.023^{\text {㧊 }}$ \\
\hline
\end{tabular}

*All HRs and rate ratios compare natalizumab to fingolimod.

†P value based on a Cox model adjusted for the baseline number of Gd+ lesions, age, baseline EDSS score and years since the first symptom (for the cumulative probability of new T1 Gd+ lesions during follow-up), from a $\chi^{2}$ test between the two treatment groups (for the number of patients with new lesions) or based on a Wilcoxon rank-sum test between the two treatment groups (for the number of new/newly enlarging T2 lesions and changes in lesion volume).

łIncludes patients with new T1 Gd+ lesions at any time point after baseline. Not all patients received treatment through 24 weeks.

$\S$ Natalizumab, $\mathrm{n}=15$; fingolimod, $\mathrm{n}=16$. Includes only patients who had MRI data through 24 weeks.

ๆCumulative probabilities at 36 weeks are reported, as no relapse events were observed after 36 weeks.

**Based on Cox model adjusted for the number of relapses in the year before baseline, age, baseline EDSS score and years since the first symptom. $\dagger+V a l u e$ indicated is a rate ratio based on a negative binomial model of ARR with treatment as effect, adjusted for the number of relapses in the year before baseline, years since the first symptom, baseline EDSS score and baseline age.

$\ddagger \ddagger P$ value based on a negative binomial model of ARR with treatment as effect, adjusted for the number of relapses in the year before baseline, years since the first symptom, baseline EDSS score and baseline age.

ARR, annualised relapse rate; EDSS, Expanded Disability Status Scale; Gd+, gadolinium enhancing; MS, multiple sclerosis; NA, not applicable. 


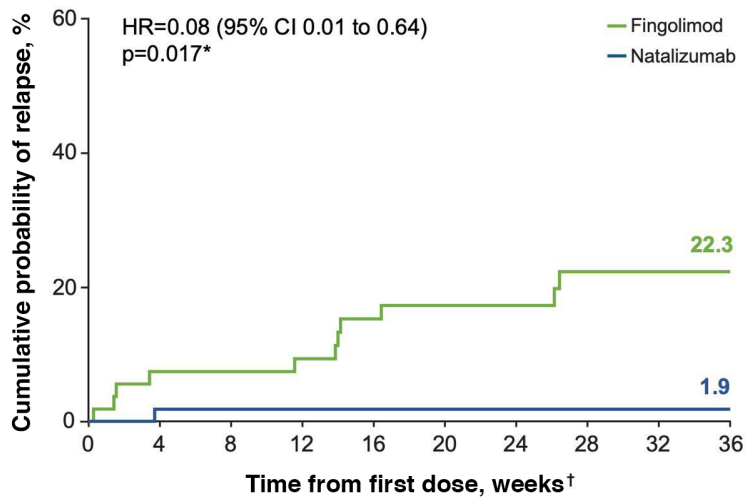

\begin{tabular}{|c|c|c|c|c|c|c|c|c|c|}
\hline \multicolumn{10}{|c|}{ Number of patients at risk } \\
\hline Natalizumab 5 & 54 & 54 & 53 & 52 & 51 & 47 & 47 & 44 & 40 \\
\hline Fingolimod 5 & 54 & 51 & 50 & 48 & 43 & 39 & 37 & 32 & 27 \\
\hline \multicolumn{10}{|c|}{ Cumulative number of patients with a relapse } \\
\hline Natalizumab & 0 & 1 & 1 & 1 & 1 & 1 & 1 & 1 & 1 \\
\hline Fingolimod & 0 & 4 & 4 & 5 & 8 & 9 & 9 & 11 & 11 \\
\hline
\end{tabular}

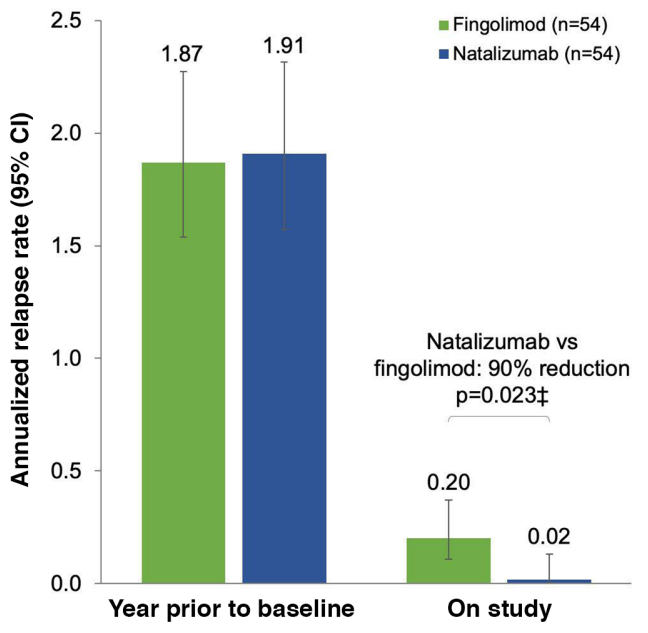

Figure 2 Impact of natalizumab versus fingolimod treatment on relapse outcomes, shown as (A) Kaplan-Meier survival curve of time to relapse over 52 weeks and (B) ARRs before study and on study. ${ }^{*}$ Natalizumab versus fingolimod, based on a Cox model adjusted for number of relapses in the year before baseline, age, baseline EDSS score and years since the first symptom. ${ }^{\dagger}$ The $\mathrm{x}$-axis has been truncated at week 36 , as no events were observed after week 36 . ${ }^{\ddagger} \mathrm{P}$ value is based on a negative binomial model of ARR with treatment as effect, adjusted for number of relapses in the year before baseline, years since the first symptom, baseline EDSS score and baseline age. ARR, annualised relapse rate; EDSS, Expanded Disability Status Scale.

fingolimod treatment groups were 1.91 and 1.87 , respectively (figure 2B). The on-treatment ARR was 0.02 in the natalizumab group (a 99\% reduction) and 0.20 in the fingolimod group (an $89 \%$ reduction). The on-treatment ARR was $90 \%$ lower with natalizumab than with fingo$\operatorname{limod}(\mathrm{p}=0.023)$.

Treatment-emergent AEs were reported for $42.6 \%$ and $59.3 \%$ of natalizumab- and fingolimod-treated patients, respectively, including two serious AEs, both in patients on fingolimod (table 2). All safety findings were consistent with the known safety profiles for natalizumab and fingolimod..$^{24}$

\section{DISCUSSION}

These unplanned exploratory analyses of REVEAL secondary endpoints indicate that natalizumab reduces $\mathrm{T} 1 \mathrm{Gd}+$ lesion accumulation and relapse disease activity soon after initiation, consistent with previous clinical trial findings. ${ }^{67}$ Treatment effects on MRI outcomes were observed within 4 weeks of starting natalizumab.

While both treatments were efficacious in patients with active RRMS, reduction in disease activity, measured by the number of new $\mathrm{T} 1 \mathrm{Gd}+$ lesions and relapses, occurred more rapidly and to a greater extent with natalizumab than with fingolimod. These results extend previous findings of the efficacy advantage of natalizumab over fingolimod in preventing relapses and reducing disease activity from comparative analyses of patients with active RRMS or prior treatment failure followed up for 1-2 years in real-world settings. ${ }^{10-13} 1519$ No significant between-group differences were observed for other MRI outcomes, such as lesion volume and the number of new/newly enlarging T2 lesions.
Safety findings in this study were consistent with the established profile of each treatment, with no new safety concerns noted. ${ }^{24} 25$

Although REVEAL was designed as a randomised controlled trial, results should be interpreted with caution, as analysis of the primary endpoint was not possible due to early study closure. However, the bias in the results due to early study termination is unlikely based on the timing of the decision (before outcome data availability) and the blinding of the sponsor and MRI readers. Secondary efficacy evaluations were limited to a relatively short treatment period of 24-36 weeks, precluding meaningful assessment of EDSS score change. A further limitation is that the longterm consequences of these relatively short-term findings are unknown.

In conclusion, the results suggest a greater benefit with natalizumab than with fingolimod in reducing relapse rates and $\mathrm{T} 1 \mathrm{Gd}+$ lesion accumulation in patients with active RRMS. The onset of efficacy occurred more rapidly with natalizumab than with fingolimod, which may be an important consideration for treatment selection in patients with active disease, who need swift and effective control of disease activity.

\section{Author affiliations}

${ }^{1}$ Department of Neuroscience, Central Clinical School, Alfred Campus, Monash University, Melbourne, Victoria, Australia

${ }^{2}$ Department of Neurology, Box Hill Hospital, Monash University, Box Hill, Victoria, Australia

${ }^{3}$ Biogen, Cambridge, Massachusetts, USA

${ }^{4}$ Piedmont HealthCare, Mooresville, North Carolina, USA

${ }^{5}$ Montreal Neurological Institute and Hospital, Montreal, Québec, Canada

${ }^{6}$ NeuroRx Research, Montreal, Québec, Canada

${ }^{7}$ Neuroimaging Research Unit, Institute of Experimental Neurology, Division of Neuroscience, San Raffaele Scientific Institute, Vita-Salute San Raffaele University, Milan, Italy 
${ }^{8}$ Department of Anatomy and Neurosciences, Section of Clinical Neuroscience, VUmc MS Center Amsterdam, VU University Medical Centre Amsterdam, Amsterdam, The Netherlands

${ }^{9}$ Biogen (at the time of these analyses), Cambridge, Massachusetts, USA

Acknowledgements The authors would like to acknowledge the contributions of the REVEAL investigators. Dr Diogo Amarante (Biogen, Cambridge, MA), who contributed substantially to the data acquisition and execution of the REVEAL trial, passed away prior to the development of this manuscript. The authors gratefully acknowledge his contributions to this study. The authors also thank Qunming Dong, formerly of Biogen, for his contributions to the initial analyses of study results. Mary Goodsell, on behalf of Ashfield Healthcare Communications (Middletown, Connecticut), wrote the first draft of the manuscript based on input from authors, and Alexandra D'Agostino, PhD, and Joshua Safran of Ashfield Healthcare Communications incorporated author feedback and edited and styled the manuscript per journal requirements.

Contributors HB, DJ, DLA, MF, JG and P-RH contributed to study design. HB, SL, DJ, DLA, MF, JG, SS, NC and P-RH were involved in analysis and interpretation of data. HB, SL and P-RH contributed to manuscript development. HB, SL, DJ, DLA, MF, JG, SS, NC and P-RH revised the manuscript for intellectual content.

Funding This study was supported by Biogen, which also provided funding for medical writing and editorial support in the development of this manuscript. Biogen reviewed and provided feedback on the manuscript. The authors had full editorial control of the manuscript and provided their final approval of all content.

Competing interests HB has received compensation for consulting from Biogen, Merck Serono and Novartis and research support from Biogen and Merck Serono. SL and NC are employees of and may hold stock and/or stock options in Biogen. DJ has received research funding from Biogen and Genentech and personal compensation for speaking or consulting services from Acorda, Bayer, Biogen, Genentech, GlaxoSmithKline, Novartis, Questcor, Serono and Teva. DLA has served on advisory boards for, received speaker honoraria from, served as a consultant for or received research support from Bayer, Biogen, Coronado Biosciences, the Consortium of Multiple Sclerosis Centers, Eli Lilly, EMD Serono, Genentech, Genzyme, GlaxoSmithKline, Merck Serono, MS Forum, NeuroRx Research, Novartis, Opexa Therapeutics, Roche, Teva, the Canadian Institutes of Health Research, the Multiple Sclerosis Society of Canada and the SA Serono Symposia International Foundation, and he holds stock in NeuroRx Research. MF is editor-in-chief of the Journal of Neurology, has received compensation for consulting services and/ or speaking activities from Biogen, Merck Serono, Novartis and Teva; and has received research support from Biogen, Merck Serono, Novartis, Roche, Teva, the Italian Ministry of Health, la Fondazione Italiana Sclerosi Multipla (FISM) and la Fondazione Italiana di Ricerca per la Sclerosi Laterale Amiotrofica (AriSLA). JG serves on the editorial boards of Multiple Sclerosis Journal and Neurology, has received speaker honoraria from Biogen, Genzyme, Merck Serono, Novartis and Teva; has received research support from Biogen; and has served on the boards of the Dutch MS Research Foundation and the Progressive MS Alliance. SS and P-RH were employees of Biogen at the time of these analyses and may hold stock and/or stock options in Biogen.

Patient and public involvement Patients and/or the public were not involved in the design, or conduct, or reporting, or dissemination plans of this research.

Patient consent for publication Not required.

Ethics approval The study was approved by ethics committees for all participating study centres.

Provenance and peer review Not commissioned; externally peer reviewed.

Data availability statement Data may be obtained from a third party and are not publicly available. Datasets from this study are not publicly available. Requests for de-identified data should be made to Biogen via established company data-sharing policies as detailed on the website http://clinicalresearch.biogen.com/.

Open access This is an open access article distributed in accordance with the Creative Commons Attribution Non Commercial (CC BY-NC 4.0) license, which permits others to distribute, remix, adapt, build upon this work non-commercially, and license their derivative works on different terms, provided the original work is properly cited, appropriate credit is given, any changes made indicated, and the use is non-commercial. See: http://creativecommons.org/licenses/by-nc/4.0/.

\section{ORCID iD}

Stephanie Licata http://orcid.org/0000-0002-7953-3867
REFERENCES

1 Polman $\mathrm{CH}, \mathrm{O}$ 'Connor PW, Havrdova E, et al. A randomized, placebo-controlled trial of natalizumab for relapsing multiple sclerosis. N Engl J Med 2006;354:899-910.

2 Kappos L, Radue E-W, O'Connor P, et al. A placebo-controlled trial of oral fingolimod in relapsing multiple sclerosis. N Engl J Med Overseas Ed 2010;362:387-401.

3 Calabresi PA, Radue E-W, Goodin D, et al. Safety and efficacy of fingolimod in patients with relapsing-remitting multiple sclerosis (freedoms II): a double-blind, randomised, placebo-controlled, phase 3 trial. Lancet Neurol 2014:13:545-56.

4 Radue E-W, O'Connor P, Polman CH, et al. Impact of fingolimod therapy on magnetic resonance imaging outcomes in patients with multiple sclerosis. Arch Neurol 2012;69:1259-69.

5 Miller DH, Soon D, Fernando KT, et al. MRI outcomes in a placebo-controlled trial of natalizumab in relapsing MS. Neurology 2007;68:1390-401.

6 Kappos L, O'Connor PW, Polman CH, et al. Clinical effects of natalizumab on multiple sclerosis appear early in treatment course. $J$ Neurol 2013;260:1388-95.

7 Miller DH, Khan OA, Sheremata WA, et al. A controlled trial of natalizumab for relapsing multiple sclerosis. N Engl J Med 2003;348:15-23.

8 Kappos L, Antel J, Comi G, et al. Oral fingolimod (FTY720) for relapsing multiple sclerosis. N Engl J Med 2006;355:1124-40.

9 Kappos L, Radue E-W, Chin P, et al. Onset of clinical and MRI efficacy occurs early after fingolimod treatment initiation in relapsing multiple sclerosis. J Neurol 2016;263:354-60.

10 Barbin L, Rousseau C, Jousset N, et al. Comparative efficacy of fingolimod vs natalizumab: a French multicenter observational study. Neurology 2016;86:771-8.

11 Baroncini D, Ghezzi A, Annovazzi PO, et al. Natalizumab versus fingolimod in patients with relapsing-remitting multiple sclerosis non-responding to first-line injectable therapies. Mult Scler 2016;22:1315-26.

12 Carruthers RL, Rotstein DL, Healy BC, et al. An observational comparison of natalizumab vs. fingolimod using JCV serology to determine therapy. Mult Scler 2014;20:1381-90.

13 Kalincik T, Horakova D, Spelman T, et al. Switch to natalizumab versus fingolimod in active relapsing-remitting multiple sclerosis. Ann Neurol 2015;77:425-35.

14 Baroncini D, Ghezzi A, Annovazzi PO, et al. Natalizumab versus fingolimod in patients with relapsing-remitting multiple sclerosis non-responding to first-line injectable therapies. Mult Scler 2016;22:1315-26.

15 Prosperini L, Saccà F, Cordioli C, et al. Real-world effectiveness of natalizumab and fingolimod compared with self-injectable drugs in non-responders and in treatment-naïve patients with multiple sclerosis. J Neurol 2017;264:284-94.

16 Braune S, Lang M, Bergmann A, et al. Second line use of fingolimod is as effective as natalizumab in a German out-patient RRMS-cohort. J Neurol 2013;260:2981-5.

17 Koch-Henriksen N, Magyari M, Sellebjerg F, et al. A comparison of multiple sclerosis clinical disease activity between patients treated with natalizumab and fingolimod. Mult Scler 2017;23:234-41.

18 Kapica-Topczewska K, Tarasiuk J, Collin F, et al. The effectiveness of interferon beta versus glatiramer acetate and natalizumab versus fingolimod in a Polish real-world population. PLoS One 2019;14:e0223863

19 Curti E, Tsantes E, Baldi E, et al. The real-world effectiveness of natalizumab and fingolimod in relapsing-remitting multiple sclerosis. an Italian multicentre study. Mult Scler Relat Disord 2019;33:146-52.

20 Preziosa P, Rocca MA, Riccitelli GC, et al. Effects of natalizumab and fingolimod on clinical, cognitive, and magnetic resonance imaging measures in multiple sclerosis. Neurotherapeutics 2020;17:208-17.

21 Vollmer BL, Nair KV, Sillau S, et al. Natalizumab versus fingolimod and dimethyl fumarate in multiple sclerosis treatment. Ann Clin Trans/ Neurol 2019;6:252-62.

22 Meca-Lallana J, Ayuso T, Martínez-Yelamos S, et al. Effectiveness of fingolimod versus natalizumab as second-line therapy for relapsingremitting multiple sclerosis in Spain: second-line gate study. Eur Neurol 2020;83:25-33.

23 World Medical Association. World medical association Declaration of Helsinki: ethical principles for medical research involving human subjects. JAMA 2013;310:2191-4.

24 Gilenya. (Fingolimod) [prescribing information]. East Hanover, NJ: Novartis, 2017

25 Tysabri. (Natalizumab) [prescribing information]. Cambridge, MA: Biogen, 2018. 